\title{
TROMBOSE CAROTÍDEA APÓS TRAUMATISMO CONTUSO
}

\author{
CAROTIDEAL THROMBOSIS AFTER BLUNT TRAUMA
}

\author{
Leonardo Ghizoni Bez, ACBC-MG ${ }^{1}$ \\ Domingos André Fernandes Drumond, TCBC-MG ${ }^{2}$
}

\section{INTRODUÇÃO}

A lesão de artéria carótida por mecanismo contuso mostra-se rara. Ocorre em cerca de $1 \%$ a $2 \%$ dos traumas cervicais contusos ${ }^{1}$. Aproximadamente $3 \%$ a $10 \%$ das lesões carotídeas provêm de traumatismos contusos ${ }^{2}$.

O diagnóstico freqüentemente apresenta-se retardado, sendo a incidência de déficits neurológicos associados alta (cerca de $40 \%$ a $80 \%)^{2}$.

O trabalho apresenta um caso de trombose carotídea por traumatismo cervical fechado. Discute as diversas modalidades terapêuticas de acordo com os achados clínicos e os exames de imagem.

\section{RELATO DO CASO}

Paciente MML, 21 anos, sexo masculino, admitido no pronto-socorro do hospital às 01:20 horas do dia $12 \mathrm{de}$ setembro de 1999 com história de libação alcoólica. Estava corado, alcoolizado, sonolento, indiferente ao contato verbal. Apresentava-se hemodinamicamente estável, aparentemente sem "déficits" motores. Feita infusão de soro fisiológico e glicose hipertônica. Por apresentar melhora do quadro de intoxicação e sem anormalidades ao exame físico, recebeu alta após três horas de sua admissão. Deixou o hospital deambulando e mantendo contato verbal espontâneo.

Retornou ao hospital às 14:46 horas do mesmo dia, com história de quadro súbito de disfasia e paresia à direita. Estava com Glasgow 15, sem queixa de cefaléia e com dificuldade de movimentação do membro superior direito. Solicitamos tomografia computadorizada de crânio, seguida de angiorressonância de crânio e região cervical. Estes exames revelaram acidente vascular cerebral (AVC) têmporoparietal isquêmico extenso à esquerda, em território de artéria cerebral média, com trombose das carótidas comum e interna esquerdas, associadas à dissecção da íntima destes vasos (Figuras 1 e 2). Instituído tratamento conservador com ácido acetilsalicílico (AAS) 325mg/dia. O paciente permaneceu internado por sete dias, sem progressão do déficit neurológico. Recebeu alta hospitalar mantendo paresia em membro superior direito e disfasia, em uso de AAS.

Admitido novamente uma semana após a alta hospitalar, com história de piora da força em membro superior direito e em membro inferior direito, que culminaram com plegia em membro superior e paresia em membro inferior. A tomografia de crânio revelou edema hemisférico cerebral esquerdo, com áreas de transformação hemorrágica têmporo-parietais. A arteriografia mostrou progressão da trombose, com oclusão completa da bifurcação carotídea, carótida interna e artéria cerebral média. Mantido trata-

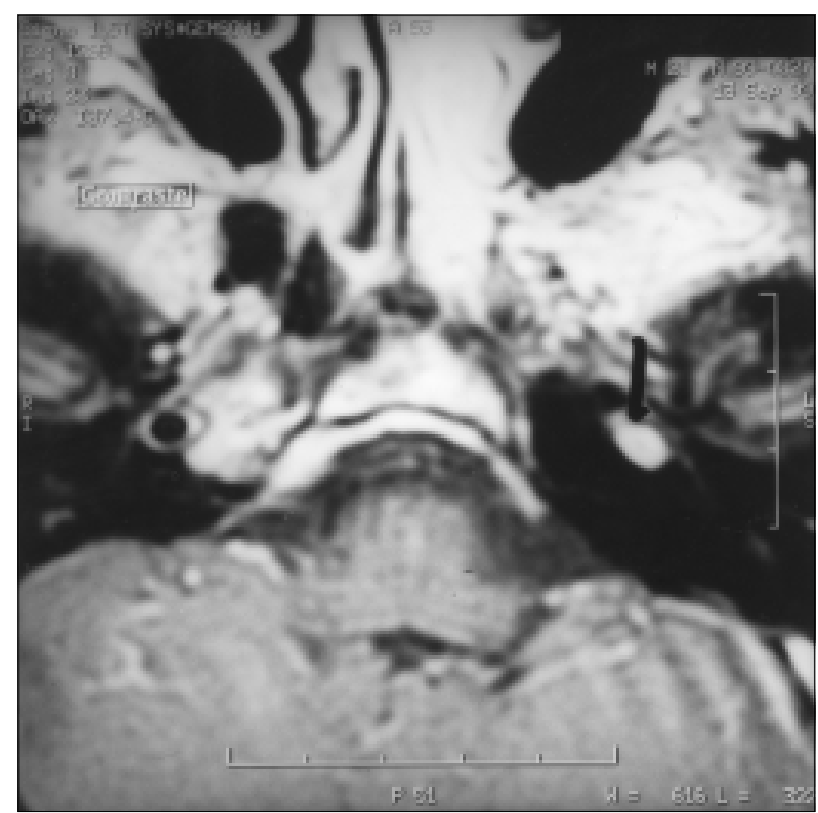

Figura 1 - Angiorressonância mostrando trombose de carótida interna esquerda.

1. Cirurgião Geral. Médico do Pronto-Socorro do Hospital Felício Rocho.

2. Cirurgião Geral. Coordenador do Pronto-Socorro do Hospital Felício Rocho.

Recebido em 7/2/2000

Aceito para publicação em 26/9/2000

Trabalho realizado no Pronto Socorro do Hospital Felício Rocho, Belo Horizonte- MG. 


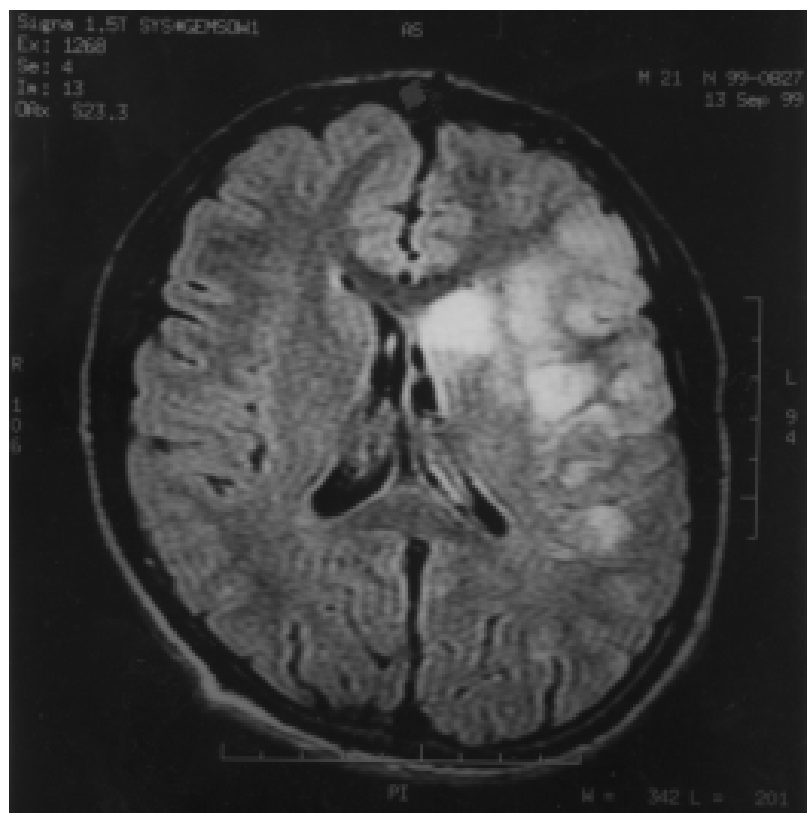

Figura 2 - Infarto têmporo-parietal isquêmico extenso.

mento de suporte clínico e antiagregante plaquetário. Alta após 15 dias, com melhora da hemiplegia e da disfasia.

\section{DISCUSSÃo}

O provável mecanismo de lesão no caso descrito foi uma hiperextensão ou rotação cervical súbitas, com estiramento da parede arterial, dissecção da camada íntima e trombose arterial secundária.

O quadro clínico nas lesões fechadas de carótidas mostra-se variável. O paciente pode permanecer assintomático, apresentar "déficit" imediato algumas horas ou até dias após o trauma. Essa variabilidade decorre em parte devido ao tipo de lesão arterial e em parte devido ao grau de circulação colateral presente. Um polígono de Willis cuja anatomia seja favorável à perfusão cerebral mesmo na vigência de oclusão carotídea está presente em cerca de $20 \%$ dos indivíduos, havendo inúmeras variações anatômicas. Um paciente com circulação colateral exuberante pode apresentar trombose completa de artéria carótida de um lado e estar assintomático ${ }^{2}$. O espectro de lesões arteriais mostra-se amplo, dentre as quais podemos citar:

- hematoma subadventicial;

- lesão intimal mínima;
- dissecção intimal com ou sem trombose arterial;

- ruptura arterial parcial com formação de pseudo-aneurisma;

- ruptura arterial para veia satélite com formação de fístula arteriovenosa;

- ruptura arterial completa.

O caso em questão envolveu uma dissecção intimal com trombose arterial de instalação insidiosa, o que levou ao surgimento de sintomatologia somente cerca de 12 horas após o trauma. Cogbill, em estudo multicêntrico sobre traumatismo fechado de carótidas, encontrou $29 \%$ de pacientes com "déficit" neurológico 12 ou mais horas após o trauma ${ }^{3}$.

A conduta nas lesões traumáticas de carótidas por trauma fechado mostra-se controversa. Segundo Colella e Diamond, ${ }^{2}$ podemos dividir os pacientes para fins de tratamento em quatro grupos:

- grupo I: tratamento cirúrgico;

- grupo II: anticoagulação (heparina e anticoagulantes orais);

- grupo III: antiagregantes plaquetários (AAS);

- grupo IV: nenhum tratamento.

O estado neurológico do paciente, a tomografia de crânio e a angiografia, além das lesões cerebrais e sistêmicas associadas, constituem importantes parâmetros para a decisão terapêutica ${ }^{4,5}$. Os pacientes sem "déficit" neurológico, com TC de encéfalo normal e angiografia mostrando fluxo carotídeo, podem ser submetidos à correção cirúrgica. A cirurgia em pacientes com "déficit" neurológico e lesões cerebrais documentadas à tomografia deve ser evitada, pois a revascularização pode levar à piora do quadro clínico, transformando um AVC isquêmico em hemorrágico ${ }^{5}$. Aqueles pacientes com traumatismo cranioencefálico (TCE) grave, hemorragia intracraniana ou outras lesões sistêmicas com potencial de sangramento não devem ser anticoagulados.

O paciente em questão não apresentava indicação de cirurgia, pois possuía "déficit" neurológico ao exame clínico e lesão cerebral à tomografia. Optou-se pelo uso de antiagregante plaquetário, com objetivo de prevenir a progressão da trombose, conforme relatos na literatura ${ }^{2}$. O uso de heparina ou anticoagulantes orais também seria uma opção para o caso, uma vez que não havia contra-indicações para anticoagulação (hemorragia intracraniana ou lesões sistêmicas associadas com potencial de sangramento).

$\mathrm{O}$ tratamento deve ser portanto individualizado. O estado neurológico do paciente, as lesões associadas e a propedêutica de imagem (TC e angiografia) mostram-se importantes fatores a serem considerados na decisão terapêutica.

\begin{abstract}
The authors report a case of thrombosis of common and internal carotid arteries caused by blunt trauma. They emphasize the rarity of this lesion and the variability of clinical presentation. Different forms of treatment are analysed, such as the use of anticoagulation and surgery. Treatment needs to be individualized for each patient.
\end{abstract}

Key Words: Carotid artery; Trauma; Contusion. 


\section{REFERÊNCIAS}

1. Schippinger G, Spork E, Obernosterer A et al. Injury of the cervical spine associated with carotid and vertebral artery occlusion: case report and literature review. Injury 1997; 28: 315.

2. Colella JJ, Diamond DL. Blunt carotid injury: reassessing the role of anticoagulation. The American Surgeon 1996; 62: 212.

3. Cogbill TH, Moore EE, Meissner M ei al. The spectrum of blunt injury to the carotid artery: a multicenter prospective. J Trauma 1994; 37: 473.

4. Kuehne JP, Weaver FA, Papanicolaou G et al. Penetrating trauma of the internal carotid artery. Arch Surg 1996; 131: 942 .

5. Murray JA, Demetriades D, Asensio JA. Carotid injury: postrevascularization hemorrhagic infarction. J Trauma 1996; 41: 760.

Endereço para Correspondência

Dr. Leonardo Ghizoni Bez

Rua Rio Verde 357/401

30310-750 - Belo Horizonte - MG

E-mail-igbez@zaz.com.br 